\title{
ESI
}

\section{PICKERING EMULSIONS OF HYDROPHILIC SILICA PARTICLES AND SYMMETRICAL ORGANIC ELECTROLYTES}

\author{
Raojun Zheng, ${ }^{a}$ Bernard P. Binks ${ }^{\mathrm{a},{ }^{*}}$ and Zhenggang Cui ${ }^{\mathrm{b}}$ \\ ${ }^{a}$ Department of Chemistry and Biochemistry, University of Hull, Hull. HU6 7RX. U.K. \\ ${ }^{b}$ The Key Laboratory of Synthetic and Biological Colloids, Ministry of Education, \\ School of Chemical and Material Engineering, Jiangnan University, 1800 Lihu Road, \\ Wuxi, P.R. China
}

No. of pages: 9

No. of Figures: 7 
Figure S1. SEM image of monodisperse silica particles with an average diameter of $1.83 \pm$ $0.04 \mu \mathrm{m}$, calculated from the image using Image $\mathrm{J}$.

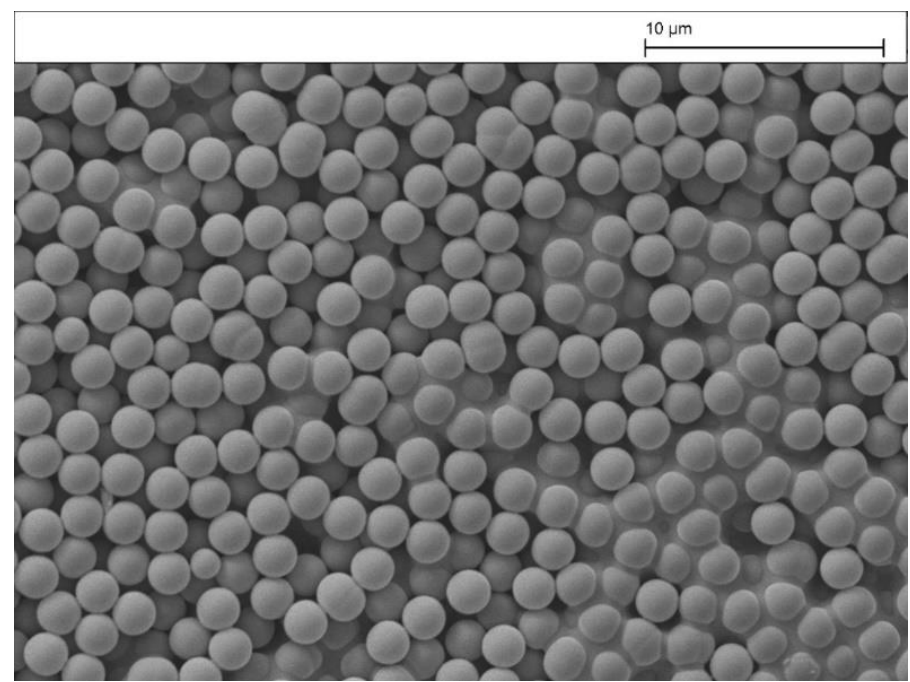


Figure S2. Appearance of octane-water emulsions (1:1 by volume) containing (a) $\mathrm{TMANO}_{3}$, (b) $\mathrm{TEANO}_{3}$, (c) $\mathrm{TPAB}$ and (d) $\mathrm{TBANO}_{3}$ at different concentrations (given) at $\mathrm{pH} 10$ taken 24 $\mathrm{h}$ after preparation. (e) Appearance of octane-water emulsions (1:1 by volume) stabilized by Ludox HS-30 silica nanoparticles in pure water at varied concentrations at $\mathrm{pH} 10$ taken $24 \mathrm{~h}$ after preparation. (f) Appearance of octane-water emulsions (1:1 by volume) stabilized by 2 wt.\% Ludox HS-30 silica nanoparticles in $\mathrm{KNO}_{3}$ solutions of varied concentration (given) at $\mathrm{pH} 10$ taken $24 \mathrm{~h}$ after preparation.
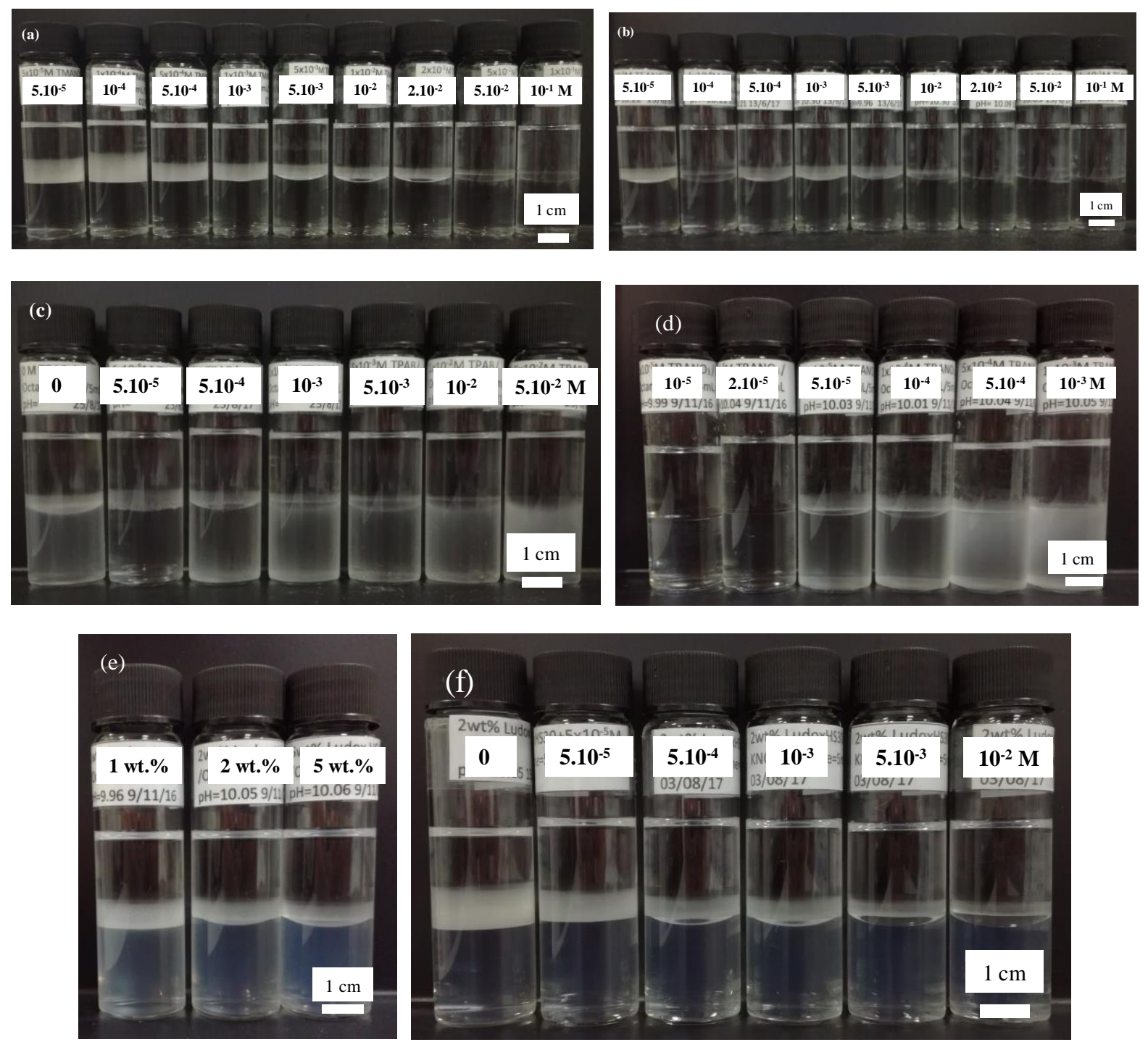
Figure S3. Appearance of $2 \mathrm{wt} . \%$ Ludox HS-30 silica dispersions at $\mathrm{pH} 10$ in the presence of (a) $\mathrm{C}_{12} \mathrm{TAB}$ and (b) $\mathrm{C}_{16} \mathrm{TAB}$ at different concentrations (given, notice sediment from $1 \times 10^{-4} \mathrm{M}$ in latter) taken immediately after preparation.
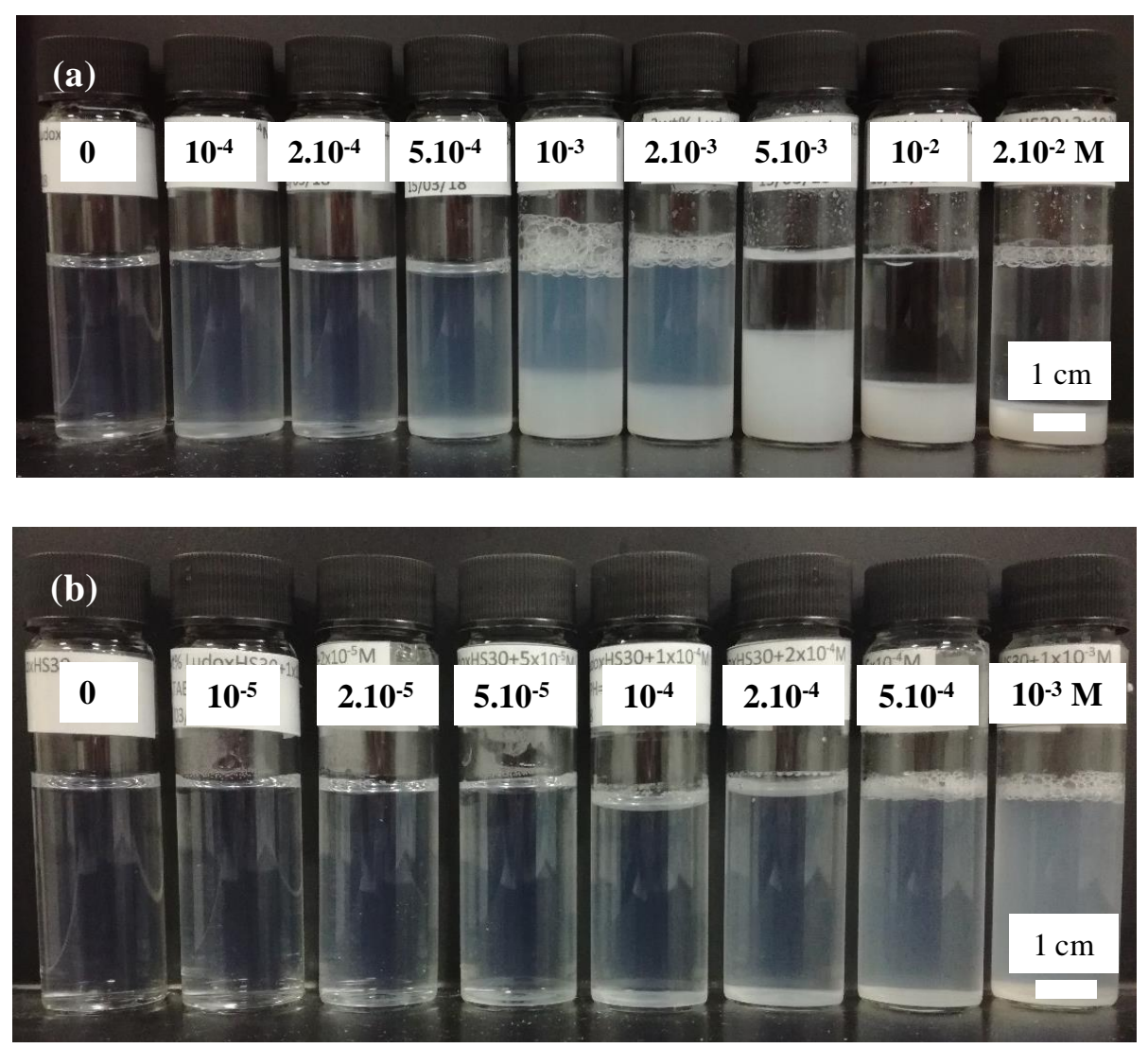
Figure S4. Appearance of octane-in-water emulsions (1:1 by volume) stabilized by 2 wt.\% Ludox HS-30 silica nanoparticles at pH 10 in the presence of (a) $\mathrm{C}_{12} \mathrm{TAB}$ and (b) $\mathrm{C}_{16} \mathrm{TAB}$ at different concentrations (given) taken 1 week after preparation.
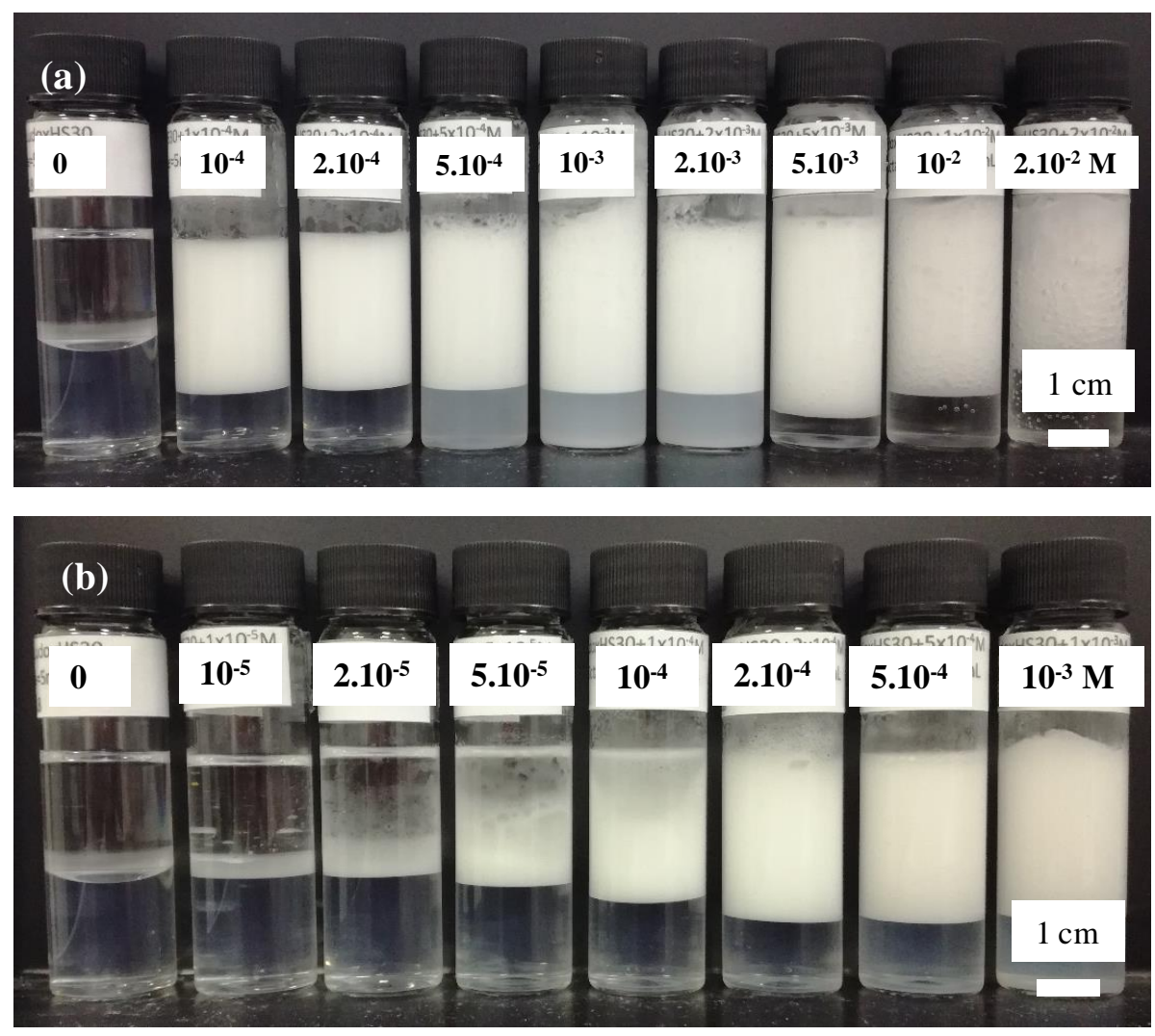
Figure S5. Variation of average inter-particle distance against [ $\left.\mathrm{TBANO}_{3}\right]$ at $\mathrm{pH} 10$ for silica particles $(d=1.83 \mu \mathrm{m})(\mathrm{a})$ on the surface of octane-in-water emulsions stabilised by $2 \mathrm{wt} . \%$ particles and (b) spread at the planar octane-water interface. The inter-particle distance is the separation between particle centres.
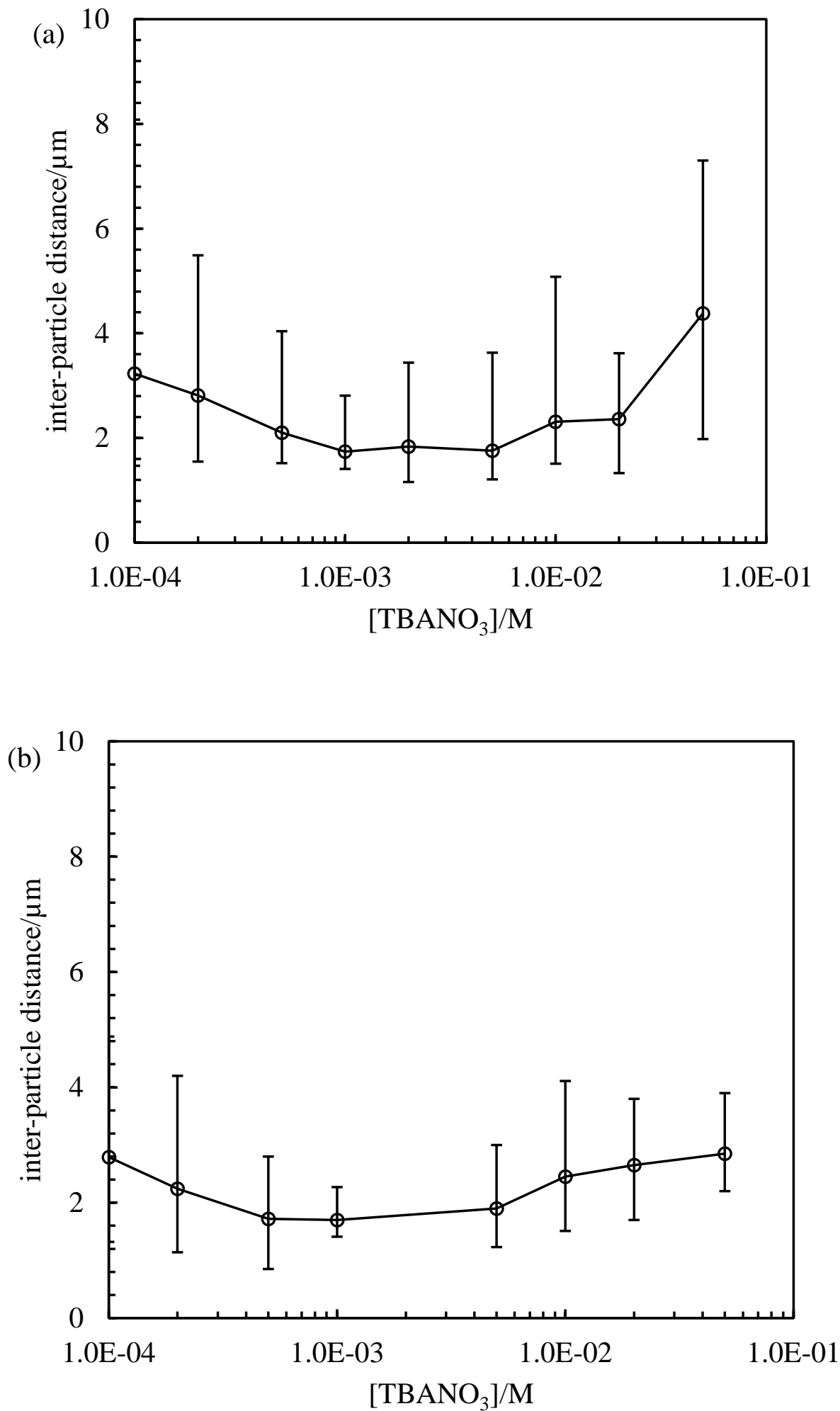
Figure S6. (a) Appearance of octane-in-water emulsions stabilized by different concentrations of silica particles $(\mathrm{d}=1.83 \mu \mathrm{m})$ in the presence of $5 \times 10^{-3} \mathrm{M} \mathrm{TBANO}_{3}$ at $\mathrm{pH} 10$ taken 2 weeks after preparation. (b) Micrographs of the surface of oil emulsion droplets in (a) immediately after preparation.
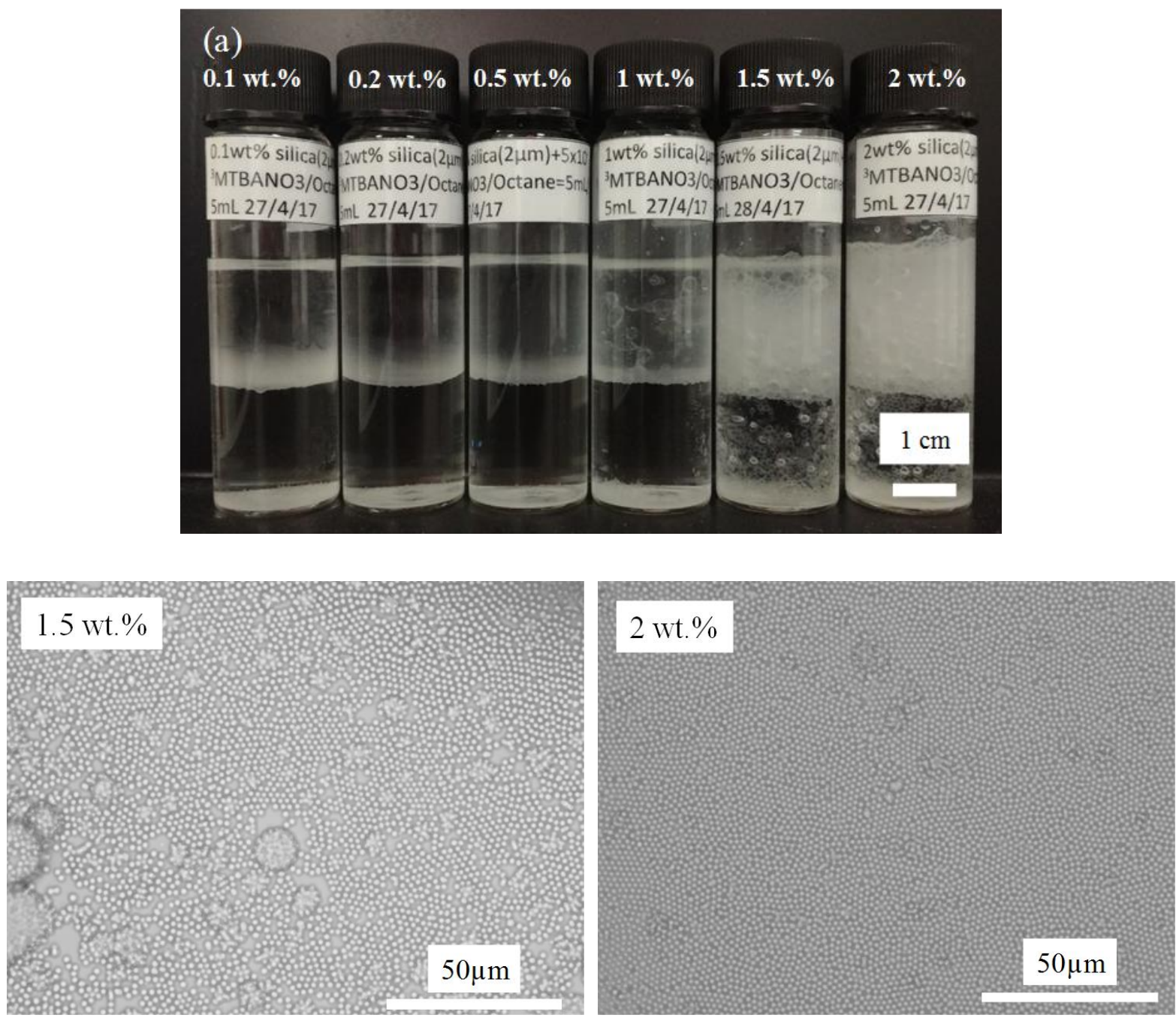
Figure S7. Selected micrographs showing silica particles spread at the planar octane-water interface by injecting $180 \mu \mathrm{L}$ of spreading solvent containing $1 \mathrm{wt} . \%$ silica particles $(\mathrm{d}=1.83$ $\mu \mathrm{m})$. Aqueous phase is either pure water or $\mathrm{TBANO}_{3}$ solution of different concentrations (given) at $\mathrm{pH} 10$. The $\mathrm{pH}$ of the spreading solvent is 10 and all images were taken immediately after spreading. The insets are enlarged portions within the red frame.
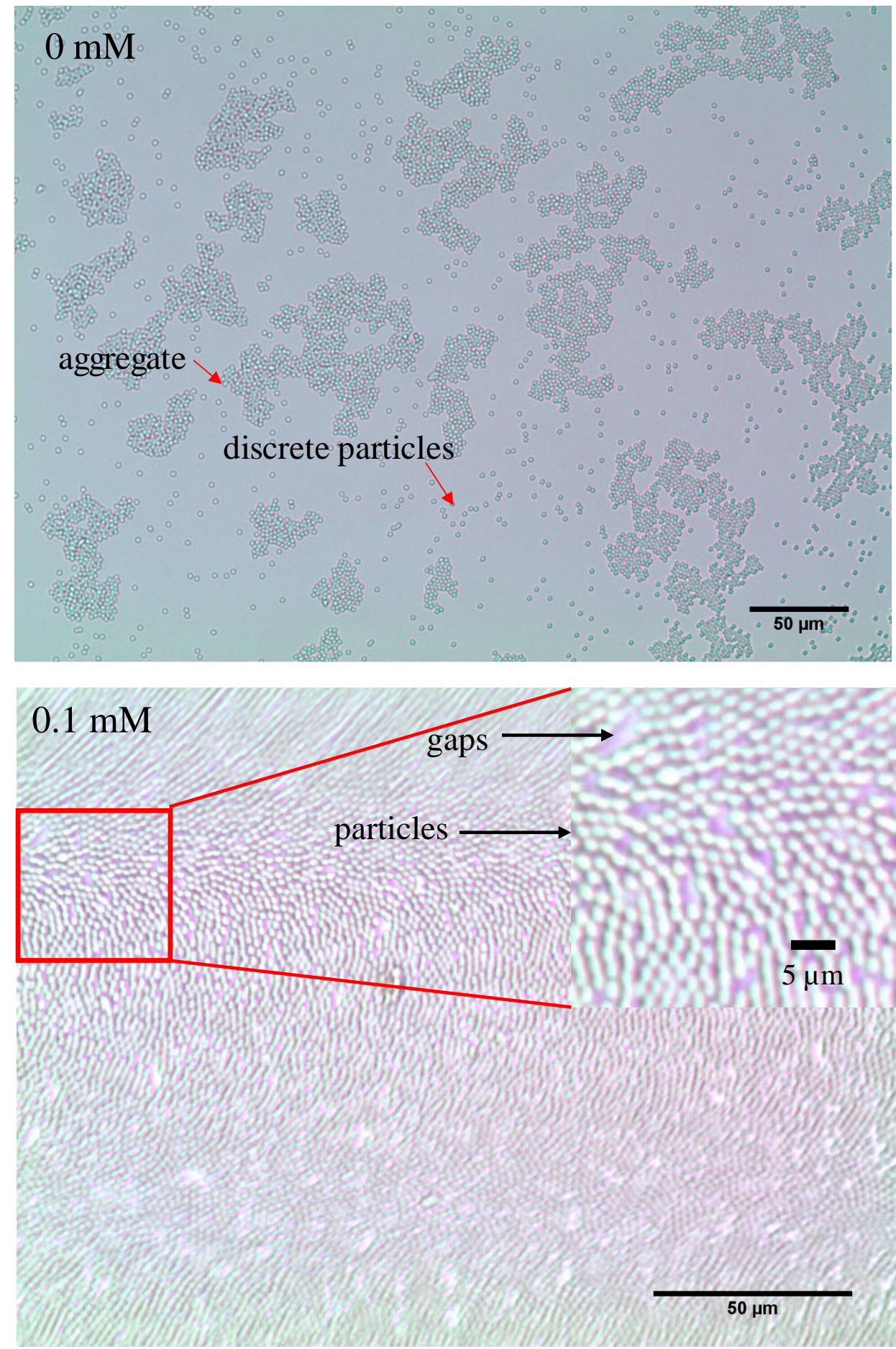

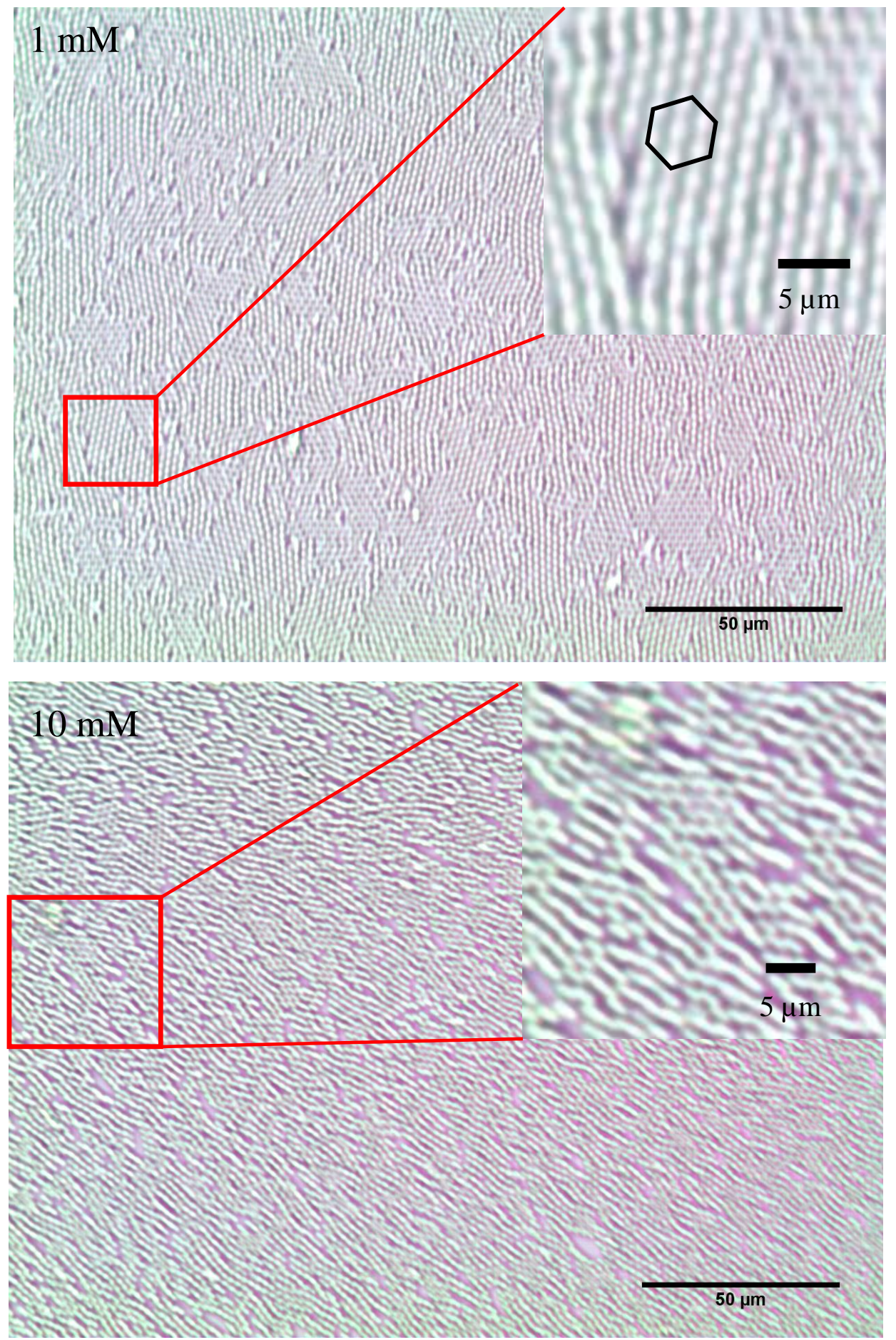